\title{
Dopamine Enhances Fast Excitatory Synaptic Transmission in the Extended Amygdala by a CRF-R1-Dependent Process
}

\author{
Thomas L. Kash, ${ }^{1 \star}$ William P. Nobis, ${ }^{2 \star}$ Robert T. Matthews, ${ }^{1,3}$ and Danny G. Winder ${ }^{1,2,3}$ \\ ${ }^{1}$ Department of Molecular Physiology and Biophysics, ${ }^{2}$ Center for Molecular Neuroscience, and ${ }^{3}$ Kennedy Center for Research on Human Development, \\ Vanderbilt University School of Medicine, Nashville, Tennessee 37232-0615
}

\begin{abstract}
A common feature of drugs of abuse is their ability to increase extracellular dopamine levels in key brain circuits. The actions of dopamine within these circuits are thought to be important in reward and addiction-related behaviors. Current theories of addiction also posit a central role for corticotrophin-releasing factor (CRF) and an interaction between CRF and monoaminergic signaling. One region where drugs of abuse promote robust rises in extracellular dopamine levels is the bed nucleus of the stria terminalis (BNST), a CRF-rich component of the extended amygdala. We find that dopamine rapidly enhances glutamatergic transmission in the BNST through activation of a combination of $\mathrm{D}_{1}$ - and $\mathrm{D}_{2}$-like receptors. This enhancement is activity-dependent and requires the downstream action of $\mathrm{CRF}$ receptor 1 (CRF-R1), suggesting that dopamine induces CRF release through a local network mechanism. Furthermore, we found that both in vivo and ex vivo cocaine induced a dopamine receptor and CRF-R1-dependent enhancement of a form of NMDA receptordependent short-term potentiation in the BNST. These data highlight a direct and rapid interaction between dopamine and CRF systems that regulates excitatory transmission and plasticity in a brain region key to reinforcement and reinstatement. Because a rise in extracellular dopamine levels in the BNST is a shared consequence of multiple classes of drugs of abuse, this suggests that the CRF-R1dependent enhancement of glutamatergic transmission in this region may be a common key feature of substances of abuse.
\end{abstract}

Key words: addiction; cocaine; glutamate; plasticity; neuropeptide; synaptic plasticity

\section{Introduction}

Drugs of abuse are thought to exert their effects on behavior through alterations of function in multiple, specific brain regions. A number of studies have demonstrated that addictive substances can alter glutamatergic synaptic plasticity in the mesolimbic dopamine system, both in the dopaminergic neurons of the ventral tegmental area (VTA) (Ungless et al., 2001, 2003; Borgland et al., 2006) and the medium spiny neurons located in the nucleus accumbens (NAc) (Thomas et al., 2001). In addition, there is increasing evidence that neuropeptide-dependent signaling mechanisms are critically involved in mediating the behavioral effects of drugs of abuse (Sarnyai et al., 2001; Borgland et al., 2006; Specio et al., 2008). In particular, several studies have demonstrated that the neuropeptide corticotrophin-releasing factor (CRF) modulates the function of dopaminergic neurons in the VTA (Ungless et al., 2003; Riegel and Williams, 2008; Wanat et al., 2008). Furthermore, it has

\footnotetext{
Received 0ct. 1, 2008; revised Nov. 10, 2008; accepted Nov. 11, 2008.

This work was supported by National Institutes of Health Grants DA19112 and AA13641 (D.G.W.) and AA017668 and AA016025 (T.L.K.). We thank Gregg Stanwood for D dopamine receptor knock-out mice. We thank Dr. Gregg Stanwood, Dr. Roger Colbran, Zoe McElligott, and Heather Gosnell for critical comments on a version of this manuscript. The confocal images presented in this manuscript were performed in part through the use of the Vanderbilt University Medical Center Cell Imaging Shared Resource.

*T.L.K. and W.P.N. contributed equally to this work.

Correspondence should be addressed to Dr. Danny G. Winder, Department of Molecular Physiology and Biophysics, 23rd and Pierce Avenue South, Room 754, RRB, Vanderbilt University School of Medicine, Nashville, TN 37232 0615. E-mail: danny.winder@vanderbilt.edu.

DOI:10.1523/JNEUROSCI.4715-08.2008

Copyright $\odot 2008$ Society for Neuroscience ～0270-6474/08/2813856-10\$15.00/0
}

been demonstrated that the bed nucleus of the stria terminalis (BNST), a component of the extended amygdala, is a source of this CRF in the VTA (Rodaros et al., 2007).

The BNST exerts a potent influence on VTA dopaminergic neuron firing (Georges and Aston-Jones, 2002). Additionally, it projects to both the lateral hypothalamus (Dong and Swanson, 2004) and paraventricular nucleus of the hypothalamus (Choi et al., 2007), regions thought to be critically involved in anxiety (Walker et al., 2003) and addiction-related behaviors (Kauer and Malenka, 2007). Similar to components of the classical reward circuitry, acute exposure to a range of abused substances (e.g., alcohol, morphine and cocaine) increases extracellular dopamine (Carboni et al., 2000) and activates neurons in a dopaminedependent manner in the BNST (Valjent et al., 2004). Moreover, pharmacological disruption of dopamine signaling in this region can alter both cocaine (Epping-Jordan et al., 1998) and alcohol-seeking (Eiler et al., 2003) behaviors. To date, however, there has been no investigation of the action of dopamine on cellular or synaptic function in the BNST. In the current study, we directly assessed the ability of dopamine to modulate neuronal function in the BNST using an $e x$ vivo slice preparation. Our studies here demonstrate a rapid and robust enhancement of excitatory transmission by dopamine in this region. Additionally, we find that the actions of dopamine are activity-dependent and require intact CRF receptor 1 (CRF-R1) signaling, suggesting that dopamine is causing release of CRF in the BNST. Our data demonstrate an acute interaction of the dopamine and CRF systems at a circuit level that involves dopaminergic regulation of CRF function rather than the converse. 

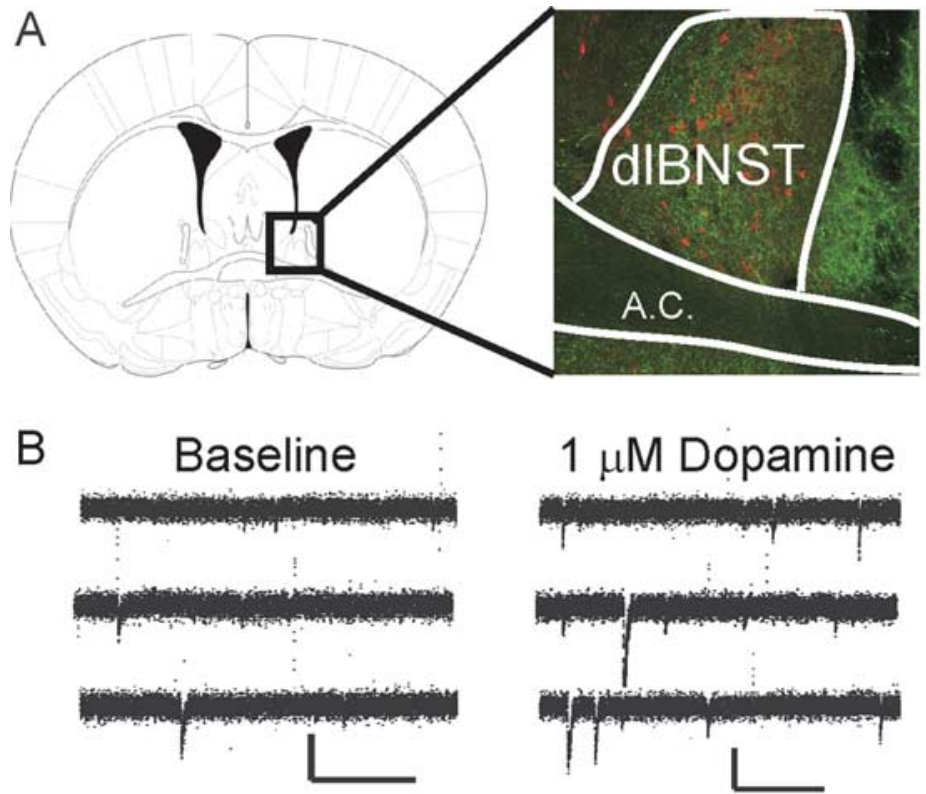

\section{$1 \mu \mathrm{M}$ Dopamine}
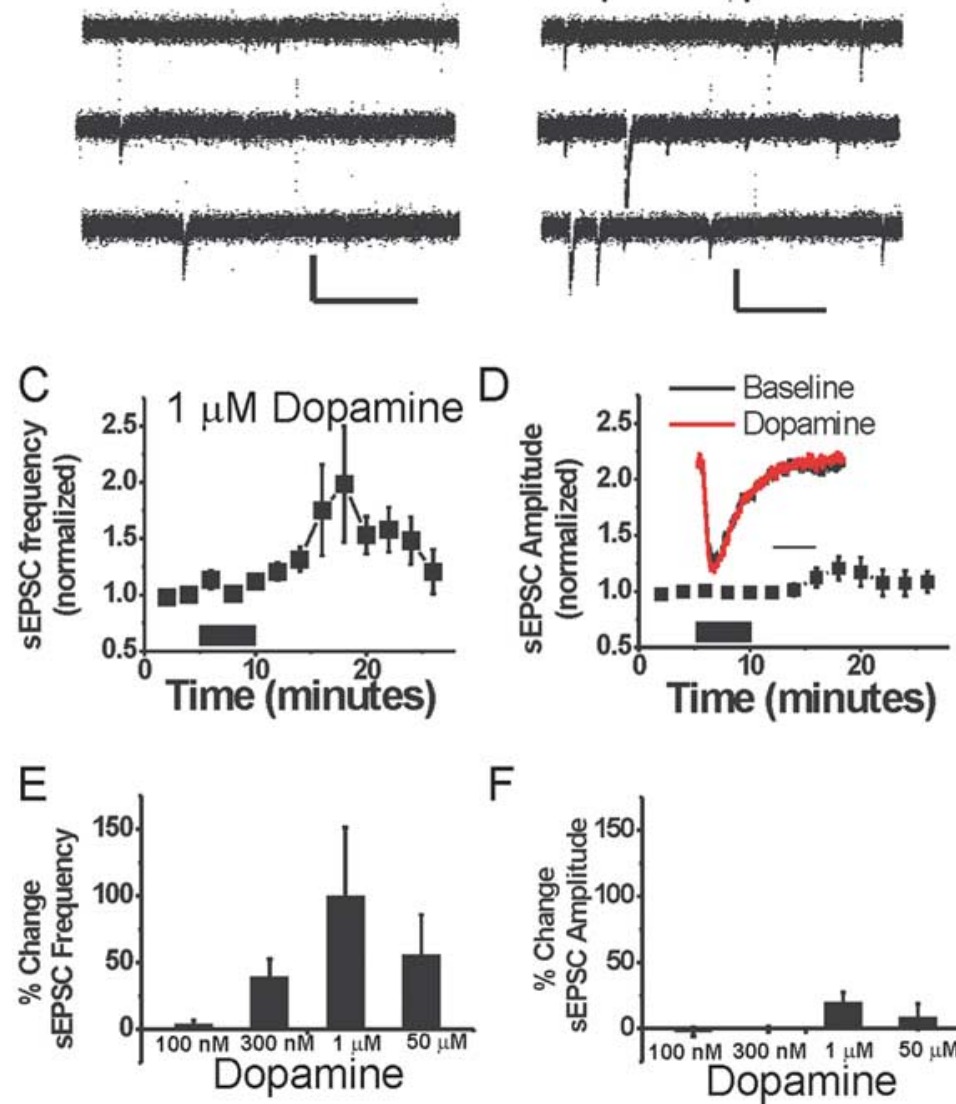

F

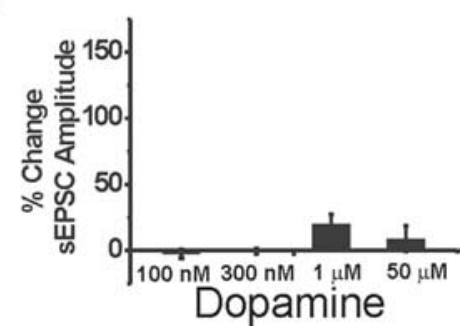

Figure 1. Dopamine enhances glutamatergic transmission in the dIBNST. $\boldsymbol{A}$, Diagram of a coronal slice adapted from mouse brain atlas outlining the position of the region of interest, the dIBNST. Immunofluorescent image demonstrates the presence of both $\mathrm{TH}+$ (green) fibers and CRF + (red) neurons within this region. $\boldsymbol{B}$, Representative sEPSC recordings in the dIBNST demonstrating the ability of dopamine to enhance glutamatergic transmission. Calibration: 25 pA, $250 \mathrm{~ms}$. C, A brief (5 min) application of $1 \mu \mathrm{m}$ dopamine transiently increases sEPSC frequency in the dIBNST. D, A brief ( $5 \mathrm{~min}$ ) application of $1 \mu$ m dopamine transiently increases sEPSC amplitude in the dIBNST. Inset, Representative normalized sEPSC traces, demonstrating the lack of effect on the kinetics of the response. Calibration: 5 ms. $\boldsymbol{E}$, Bar graph demonstrating the concentration-dependent effects of dopamine on sEPSC frequency in the dIBNST. $\boldsymbol{F}$, Bar graph demonstrating the effects of multiple concentrations of dopamine on sEPSC amplitude in the dIBNST.

\section{Materials and Methods}

Brain slice preparation and electrophysiology. All procedures were performed according to Vanderbilt University Institutional Animal Care and Use Committee approved procedures. Brain slices were prepared from 6- to 8-week-old male C57BL/6 mice, and recordings were performed as described previously (Weitlauf et al., 2004; Kash and Winder, 2006; Kash et al., 2008). For whole-cell voltage-clamp recordings, AMPA-mediated spontaneous EPSCs (sEPSCs) were recorded from a holding potential of $-70 \mathrm{mV}$ and pharmacologically isolated by adding $25 \mu \mathrm{M}$ picrotoxin to ACSF [ACSF: (in mM) $124 \mathrm{NaCl}, 4.4 \mathrm{KCl}, 2 \mathrm{CaCl}_{2}$, 1.2 $\mathrm{MgSO}_{4}, 1 \mathrm{NaH}_{2} \mathrm{PO}_{4}, 10.0$ glucose, and $\left.26.0 \mathrm{NaHCO}_{3}\right]$. sEPSC recordings were acquired in $2 \mathrm{~min}$ gap-free blocks. Recording electrodes for voltage-clamp sEPSC experiments were filled with (in $\mathrm{mm}$ ) $135 \mathrm{Cs}^{+}$- gluconate, $5 \mathrm{NaCl}, 10$ HEPES, 0.6 EGTA, 4 ATP, 0.4 GTP, pH 7.2, 290-295 mOsmol. Recording electrodes for current-clamp experiments were filled with (in $\mathrm{mm}$ ) $135 \mathrm{~K}^{+}$. gluconate, $5 \mathrm{NaCl}, 10$ HEPES, 0.6 EGTA, 4 ATP, 0.4 GTP, pH 7.2, 290-295 mOsmol. For experiments in which the effects of antagonists were determined, the antagonist was applied for at least $15 \mathrm{~min}$ before application of the agonist and then remained on for at least $10 \mathrm{~min}$ following removal of agonist. In the experiments where $100 \mathrm{~nm} \mathrm{CRF}$ and $300 \mathrm{~nm}$ Urocortin 1 were applied, the application lasted for 15 and $10 \mathrm{~min}$ respectively to ensure sufficient slice wash-in. For current-clamp experiments, before application of dopamine, cells were held at least $10 \mathrm{~min}$, or until the resting membrane potential stabilized.

For field recordings, following dissection, slices were transferred to an interface chamber where they were perfused with heated $\left(29-30^{\circ} \mathrm{C}\right)$ oxygenated ACSF at a rate of $2 \mathrm{ml} /$ min. Slices were allowed to equilibrate for at least $1 \mathrm{~h}$ before recording. A bipolar nichrome stimulating electrode was placed dorsally to the recording electrode within the dorsal-lateral BNST (dlBNST) such that stimulation of the field resulted in a distinguishable N1 [the tetrodotoxin (TTX)-sensitive fiber volley estimate] and N2 [6-cyano-7-nitroquinoxaline-2,3dione (CNQX)-sensitive synaptic response]. Baseline recordings at a stimulus intensity that produced $\sim 40 \%$ of the maximum response were recorded for at least $20 \mathrm{~min}$ before applying drug or tetanizing the slice. Field recording experiments in which cocaine was applied without stimulation/recording were found to have no significant difference from those in which the slice was recorded from throughout the time course (supplemental Fig. $1 A, B$, available at www.jneurosci.org as supplemental material) (Student's $t$ test, $p=0.59$ ). As such, both types of experiments were grouped together in our measurements. Throughout the experiment the N1 was monitored for changes that would indicate a change in the estimate of the number of fibers excited or alterations in the health of the slice and experiments were not included in the analysis if $\mathrm{N} 1$ amplitudes changed by $\pm 20 \%$ of baseline recordings for longer than $10 \%$ of the recorded points. For data analysis, recordings were normalized to the $10 \mathrm{~min}$ before tetanus. All recordings were made using either Clampex 8.2 or 9.2 and analyzed using Clampfit 9.2 (Molecular Devices).

Statistical analyses. Statistical analyses were performed using Microsoft Excel, GraphPad Prism, Microcal Origin, and MATLAB 7.4. Specifically, when determining if a compound had a significant effect, a Student's paired $t$ test was used, comparing the baseline value to the experimental value. To compare the effects of different antagonists on cocaine-induced alterations in function, a one-way ANOVA was used, followed by Tukey's post-test to determine the significance of specific comparisons. To assess drug effects on short-term potentiation (STP), the area under the curve was calculated and used for statistical analysis. To estimate the area under the curve the percent above baseline for each $1 \mathrm{~min}$ bin for 0-20 min after the tetanus was calculated and summed together for each experiment. Mean and variance were then calculated. All values given for drug effects throughout the study are presented as average \pm SEM. For results given in figures, significance is noted in the figure legend. For results not included in figures, significance is noted in the text. 
Pharmacology. The drugs cocaine (Sigma, National Institute on Drug Abuse), flupenthixol (Sigma), NBI-27914 (Sigma), Astressin-2B (Tocris), SCH23390 (Tocris), sulpiride (Tocris), picrotoxin (Tocris) and DLAPV (Tocris) were bath applied at final concentrations which are noted in the experimental design. Dimethylsulfoxide (DMSO) is the solvent used for stock solutions of NBI27914 where the maximum final concentration of DMSO was $0.02 \%$ by volume.

Knock-out animals. $\mathrm{D}_{1} \mathrm{R}$ knock-out (KO) breeder animals extensively backcrossed onto C57BL/6J were obtained from Dr. Gregg Stanwood (Department of Pharmacology, Vanderbilt University Medical Center, Nashville, TN) and were generated as previously reported (Stanwood et al., 2006).

Colchicine injections and immunohistochemistry. C57BL/6 male mice, 10-12 weeks old, were group housed and provided with food and water ad libitum. On the day of surgery, mice were anesthetized with tribromoethanol (dissolved in tert-amyl alcohol and diluted to $2.5 \%$ with sterile saline just before use; $0.12-0.22$ $\mathrm{ml} / 10 \mathrm{~g}$ body weight, i.p.) and placed in a stereotaxic apparatus (myNeuroLab). Angle Two software was used for setting an injection target within one of the lateral ventricles (coordinates were $0.48 \mathrm{~mm}$ posterior to bregma, $1.0 \mathrm{~mm}$ lateral to the midline and $2.8 \mathrm{~mm}$ below the skull surface). Surgery and postoperative care were performed as described previously (Kash et al., 2008). Each mouse was given a single intraventricular injection of colchicine $(20 \mu \mathrm{g}$ in $2 \mu \mathrm{l}$ of sterile saline) at $50 \mathrm{nl} / \mathrm{min}$ using a WPI nanoinjector fitted with a $5 \mu \mathrm{l}$ syringe and 34 gauge needle. Postsurgical care included subcutaneous saline ( $1.0 \mathrm{ml}$ per $20 \mathrm{~g}$ of body weight) and analgesic (buprenorphen, $0.1 \mathrm{mg} / \mathrm{kg}$ ) injections every $12 \mathrm{~h}$. After surgery (24-36 h), mice were overdosed with Nembutal (100 mg/kg, i.p.) and perfused through the left ventricle of the heart with ice-cold phosphate buffered saline $(10 \mathrm{ml})$ followed by cold $4 \%$ paraformaldehyde (20 $\mathrm{ml}$ ). Brains were removed, postfixed for $24 \mathrm{~h}$ at $4^{\circ} \mathrm{C}$ in the same fixative and then cryoprotected in $30 \%$ sucrose. $40 \mu \mathrm{m}$ coronal sections of forebrain were cut on a cryostat (Leica, CM 3050 S) and stored in PBS before fluorescent immunohistochemical staining.

Brain sections containing the BNST were washed in 4 changes of PBS, incubated for $1 \mathrm{~h}$ in PBS plus $0.5 \%$ Triton X-100, incubated for $2 \mathrm{~h}$ in PBS plus $0.1 \%$ Triton $\mathrm{X}-100$ and $10 \%$ normal donkey serum, washed, and then incubated with mouse anti-tyrosine hydroxylase monoclonal antibody (Immunostar, 1:2000), rabbit anti-CRF polyclonal anti-serum (Peninsula Laboratories, 1:1000) for $48 \mathrm{~h}$ at $4^{\circ} \mathrm{C}$, washed $(4 \times 10 \mathrm{~min})$, incubated with CY5-conjugated $\mathrm{F}\left(\mathrm{ab}^{\prime}\right)$ fragment donkey anti-rabbit IgG (Jackson ImmunoResearch, 1:400) and CY2-conjugated F( $\mathrm{ab}^{\prime}$ ) fragment donkey anti-mouse IgG (Jackson ImmunoResearch, 1:150) overnight at $4^{\circ} \mathrm{C}$. Stained slices were then washed $(4 \times 10 \mathrm{~min})$, mounted on slides with Aquamount and imaged with a Zeiss LSM510 confocal microscope. Images were analyzed with Zeiss LSM Image Browser software.

\section{Results}

Dopamine produces activity-dependent enhancement of spontaneous glutamatergic transmission through $\mathrm{D}_{1}$ - and $\mathrm{D}_{2}$-like dopamine receptors

We measured sEPSCs recorded from neurons located in the dlBNST (Fig. 1A) (average basal frequency, $1.8 \pm 0.4 \mathrm{~Hz}$; average
B
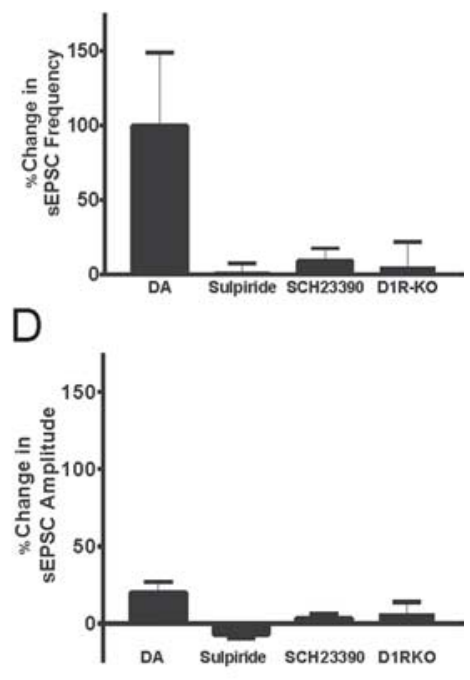

Time (minutes)

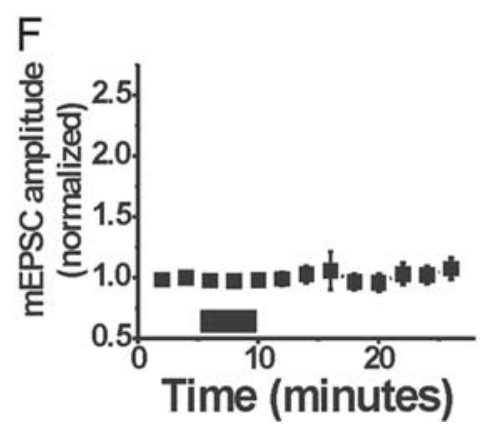

Figure 2. Activation of both $\mathrm{D}_{1}$-like and $\mathrm{D}_{2}$-like receptors is required for dopamine enhancement of spontaneous glutamatergic transmission in the dIBNST. $A$, A brief application of dopamine $(1 \mu \mathrm{M})$ does not alter sEPSC frequency in the presence of either the $\mathrm{D}_{1}$-like receptor antagonist $\mathrm{SC} 23390$ or the $\mathrm{D}_{2}$-like receptor antagonist sulpiride. $\boldsymbol{B}$, Bar graph demonstrating dopamine does

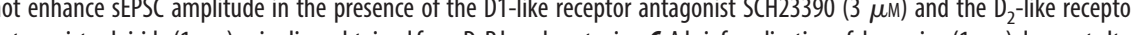
, Bar graph demonstrating dopamine does not enhance $S E P S C$ amplitude in the presence of the $\mathrm{D}_{1}$-like receptor antagonis $S C H 23390$ and the $D_{2}$-like receptor antagonist sulpiride or in slices obtained from $D_{1} R$ knock-out mice. $E$, A brief (5 min) application of $1 \mu \mathrm{m}$ dopamine does not alter the frequency of $\mathrm{mEPSC}(\mathrm{s}$ in the BNST. $\boldsymbol{F}, \mathrm{A}$ brief $(5 \mathrm{~min})$ application of $1 \mu \mathrm{m}$ dopamine does not alter the amplitude of mEPSCs in the BNST.

basal amplitude, $22 \pm 2 \mathrm{pA}, n=16$ ) (Fig. $1 B$, representative trace). We focused on this particular region of the BNST based on previous findings that (1) neurons in this region have been shown to be activated by acute administration of drugs of abuse (Valjent et al., 2004); (2) it receives a dopaminergic input (Fig. 1A) (Meloni et al., 2006; Healey et al., 2008); and (3) multiple substances of abuse promote robust rises in extracellular dopamine levels in this region (Carboni et al., 2000). We focused our efforts on modulation of sEPSCs instead of evoked EPSCs because of the complex nature of the glutamatergic projections to the BNST. To test the hypothesis that dopamine modulates glutamatergic synaptic transmission in the dlBNST, dopamine $(1 \mu \mathrm{M})$ was bath applied for $5 \mathrm{~min}$ while spontaneous glutamatergic transmission was monitored using whole-cell patch-clamp recordings in acutely prepared mouse brain slices. We found that this brief dopamine application resulted in a transient increase in the frequency of sEPSCs (198 $\pm 51 \%$ of basal frequency, $p<0.05, n=$ 10) (Fig. $1 C, E$ ). Additionally, there was a modest, but significant effect on sEPSC amplitude (120 $\pm 10 \%$ of basal frequency, $p<$ $0.05, n=10$ ) (Fig. $1 D$ ) with no apparent effect on the kinetics of 


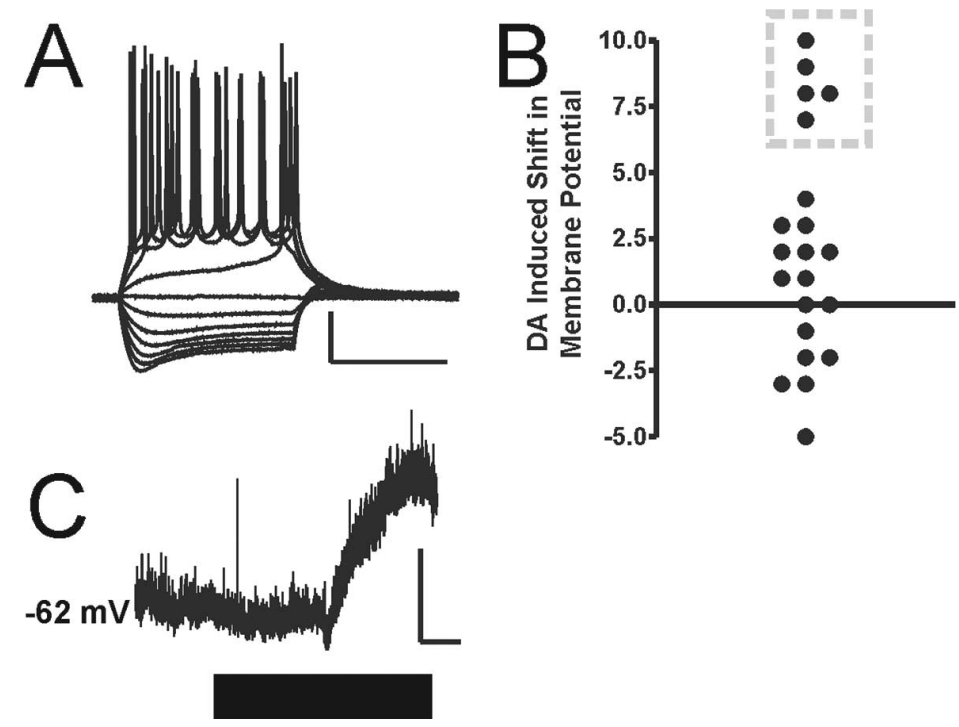

Figure 3. Dopamine increases excitability in a subpopulation of neurons in the BNST. $A$, Representative current-clamp recording from a neuron in the dBNST that was depolarized by dopamine. Each individual trace reflects a current injection ranging from -30 to $40 \mathrm{pA}$ with a $10 \mathrm{pA}$ interval. Calibration: $20 \mathrm{mV}, 200 \mathrm{~ms}$. B, Scatter plot demonstrating that dopamine application resulted in a depolarization in a subpopulation of neurons. Neurons that were dramatically depolarized by dopamine are highlighted by a dashed box. $C$, Representative recording in a dopamine-responsive neuron demonstrating the depolarizing shift following bath application of $1 \mu \mathrm{m}$ dopamine. Calibration: $5 \mathrm{mV}, 1 \mathrm{~min}$.

the sEPSC (Fig. 1D, inset, normalized sEPSC trace). We then examined the ability of different concentrations of dopamine to modulate spontaneous glutamatergic transmission in the dlBNST. We found that dopamine exhibited a concentrationdependent enhancement of spontaneous glutamatergic synaptic transmission (Fig. 1E) (100 nM dopamine, $100 \pm 3 \%$ of basal frequency, $n=5 ; 300 \mathrm{nM}, 130 \pm 6 \%$ of basal frequency, $n=5 ; 50$ $\mu \mathrm{M}, 165 \pm 39 \%$ of basal frequency, $n=6)$ (Fig. $1 F)(100 \mathrm{~nm}$ dopamine, $98 \pm 3 \%$ of basal amplitude, $n=5 ; 300 \mathrm{~nm}, 99 \pm 2 \%$ of basal amplitude, $n=5 ; 50 \mu \mathrm{M}, 109 \pm 10 \%$ of basal amplitude, $n=6)$.

Dopamine can act at adrenergic receptors (Malenka and Nicoll, 1986) in addition to dopamine receptors. Thus, we wanted to establish whether dopamine was enhancing spontaneous glutamatergic transmission in the dlBNST through activation of dopamine receptors. We found that preapplication of either a $\mathrm{D}_{1}$-like receptor antagonist $(\mathrm{SCH} 23390,3 \mu \mathrm{M}, 94 \pm 6 \%$ of basal frequency, $n=5$ ) or a $\mathrm{D}_{2}$-like receptor antagonist (sulpiride, 1 $\mu \mathrm{M}, 101 \pm 7 \%$ of basal frequency, $n=4,10 \mu \mathrm{M}, 113 \pm 10 \%$ of basal frequency, $n=7$, data not shown) prevented dopamineinduced increases in sEPSC frequency (Fig. $2 A, B$ ) and sEPSC amplitude (Fig. 2C,D). Additionally, we found that neither SCH23390 (3 $\mu \mathrm{M}, 83 \pm 14 \%$ of basal frequency, $n=4 ; 99 \pm 7 \%$ of basal amplitude, $n=4)$ nor sulpiride ( $1 \mu \mathrm{M}, 96 \pm 5 \%$ of basal frequency, $n=4 ; 103 \pm 5 \%$ of basal amplitude, $n=4$ ) alone altered sEPSC amplitude or frequency, suggesting a lack of tonic activation of $\mathrm{D}_{1}$ - and $\mathrm{D}_{2}$-like receptors in the dlBNST. Furthermore, we found that in slices obtained from $\mathrm{D}_{1} \mathrm{R}$ KO mice, dopamine did not alter sEPSC frequency $(99 \pm 18 \%$ of basal frequency, $n=6$ ) (Fig. $2 B$ ) or sEPSC amplitude (106 $\pm 8 \%$ of basal frequency, $n=6$ ) (Fig. $2 D$ ). Together, the results obtained from these converging genetic and pharmacological approaches suggest that dopamine enhances spontaneous glutamatergic transmission in the dlBNST via activation of both $\mathrm{D}_{1^{-}}$and $\mathrm{D}_{2}$-like receptors.

To more clearly understand the mechanism of action of do- pamine in the dlBNST, we next examined the ability of dopamine to modulate miniature EPSCs (mEPSCs). By examining the effect of a compound on mEPSCs, one can more precisely determine if the locus of action is pre or postsynaptic. mEPSCs were isolated by addition of the sodium channel blocker TTX $(1 \mu \mathrm{M})$ to the bath solution (average basal frequency, $1.4 \pm$ $0.4 \mathrm{~Hz}$; average basal amplitude, $23 \pm 1$ $\mathrm{pA}, n=10)$. Surprisingly, we found that in the presence of TTX, dopamine did not alter either mEPSC frequency ( $95 \pm 5 \%$ of basal frequency, $n=5$ ) (Fig. $2 G$ ) or amplitude (95 $\pm 8 \%$ of basal frequency, $n=5$ ) (Fig. $2 H$ ). This suggests that dopamine is acting to alter glutamatergic transmission via an activity-dependent mechanism.

To further examine the activity dependence of the dopamine regulation of excitatory transmission, we measured the ability of dopamine to modulate the excitability of neurons in the dlBNST using the current-clamp recording configuration (Fig. 3A, representative currentclamp recording). We found that dopamine had negligible effects on the resting membrane potential in the majority of the cells in the dlBNST (18 of 23) (Fig. 3B). However, we found that in a subpopulation of neurons ( 5 of 23 ) dopamine application led to a marked transient depolarization $(8.4 \pm 0.5 \mathrm{mV}, n=5, p<0.05)$ that partially reversed $(2.4 \pm 1.2 \mathrm{mV}, n=5)$ (Fig. $3 B, C$ ), inducing spontaneous action potential firing in 3 of 5 neurons and increasing current-injection-induced firing of action potentials in 4 of 5 neurons. A comparison of the properties of the neurons that were robustly depolarized by dopamine compared with those that were not dramatically altered showed no significant differences in capacitance, input resistance, resting membrane potential or presence of hyperpolarization-activated current (data not shown). The ability of dopamine to robustly depolarize a subpopulation of neurons in the dIBNST is similar to what has been previously noted with application of serotonin in currentclamp recordings in the dlBNST (Rainnie, 1999).

\section{Dopamine-induced enhancement of glutamatergic transmission requires CRF signaling}

The combined findings that dopamine enhancement of glutamate transmission is activity dependent, and that only a subset of dlBNST neurons are robustly depolarized by dopamine suggest that dopamine could enhance glutamatergic transmission indirectly by depolarizing a subpopulation of dlBNST neurons to produce the release of a neurotransmitter or neuropeptide which then directly regulates glutamatergic transmission. Several studies, both functional (Meloni et al., 2006) and anatomical (Phelix et al., 1994), have demonstrated an interaction between dopamine and CRF in the BNST. Indeed, a subpopulation of neurons within the dlBNST are CRF positive (Day et al., 1999; Rodaros et al., 2007). Using dual-label fluorescent immunohistochemistry in colchicine-injected mice, we found that CRF-immunoreactive neurons in the dlBNST are closely apposed to tyrosine hydroxylase $(\mathrm{TH})$ positive fibers (Fig. $4 A$ ), consistent with previous findings obtained using electron microscopy (Phelix et al., 1994).

We hypothesized that dopamine alters glutamatergic trans- 
mission through activation of endogenous CRF signaling in the dlBNST. In keeping with this hypothesis, we found that preapplication of the selective CRF-R1 antagonist NBI27914 (Chen et al., 1996) (1 $\mu \mathrm{M})$ inhibited dopamine-induced increases in sEPSC frequency $(96 \pm 11 \%$ of basal frequency, $n=6$ ) (Fig. $4 B$ ). We next examined the ability of exogenously applied CRF to modulate glutamatergic transmission in the dlBNST. We found that bath application of $300 \mathrm{~nm}$ CRF increased sEPSC frequency $(140 \pm 14 \%$ of basal frequency, $p<0.05, n=6$ ) (Fig. $4 C, E$ ) but not sEPSC amplitude (117 $\pm 15 \%$ of basal amplitude, $n=6$ ) (Fig. $4 D, F)$. We then examined the ability of different concentrations of CRF to modulate spontaneous glutamatergic transmission in the dlBNST. We found that CRF exhibited a concentration-dependent enhancement of sEPSC frequency (Fig. 4E) (100 nM CRF, $100 \pm 3 \%$ of basal frequency, $n=5$; $300 \mathrm{~nm} \mathrm{CRF}, 130 \pm 6 \%$ of basal frequency, $n=5 ; 1 \mu \mathrm{M}$ CRF, $165 \pm 39 \%$ of basal frequency, $n=6$ ) but not sEPSC amplitude (Fig. $4 F$ ).

Additionally, we examined the ability of Urocortin 1, an endogenous agonist of CRF receptors (Vaughan et al., 1995), to modulate spontaneous glutamatergic transmission in the dlBNST. Similar to CRF, we found that bath application of $300 \mathrm{nM}$ Urocortin 1 increased in sEPSC frequency $(228 \pm 40 \%$ of basal frequency, $p<0.05, n=8$ ) (Fig. $4 G$ ) but not sEPSC amplitude (104 $\pm 5 \%$ of basal amplitude, $n=8$ ) (Fig. $4 H$ ).

Next, we sought to determine the receptor subtype through which CRF is enhancing glutamatergic function in the dlBNST. We found that preapplication of NBI27914 $(1 \mu \mathrm{M})(97 \pm 7 \%$ of basal frequency, $n=7$ ) (Fig. $5 A, B$ ), but not the CRF-R2 antagonist, Astressin-2B (100 nM) (107 $\pm 49 \%$ of basal frequency, $p<0.05$, $n=5$ ) (Fig. 5A,B), blocked the ability of $300 \mathrm{~nm}$ CRF to enhance spontaneous glutamatergic transmission. Additionally, we found that CRF did not alter sEPSC amplitude in the presence of either the CRF-R1 or the CRF-R2 antagonists (Fig. 5C,D). Furthermore, we found that the ability of CRF to enhance spontaneous glutamatergic transmission persisted in the presence of SCH23390 (10 $\mu \mathrm{M}$, $150 \pm 14 \%$ of basal frequency, $p<0.05, n=4$ ).

There have been previous reports that CRF receptors can be tonically active in slice preparations (Liu et al., 2004). We examined the tonic-activity of CRF receptors in the dlBNST in our slice preparation by examining the ability of either NBI27914 or Astressin-2B alone to modulate spontaneous glutamatergic transmission. Interestingly, we found that application of NBI277914 led to a modest but significant reduction of sEPSC frequency ( $90 \pm 3 \%$ of basal frequency, $n=4)$ but not amplitude
(102 $\pm 4 \%$ of basal amplitude, $n=4$ ), whereas Astressin-2B had no effect on spontaneous glutamatergic transmission (101 $\pm 10 \%$ of basal frequency, $n=5 ; 104 \pm 5 \%$ of basal amplitude, $n=5)$. This suggests that CRF-R1 may tonically regulate glutamate release in our dlBNST slice preparation.

We then sought to determine the mechanism by which CRF was enhancing glutamatergic function in the dlBNST by examining CRF modulation of mEPSCs. In contrast to dopamine, we found that in the presence of TTX, CRF enhanced mEPSC frequency (145 $\pm 8 \%$ of basal frequency, $p<0.05, n=$ 5) (Fig. 5G, inset) but not amplitude (100 $\pm 2 \%$ of basal amplitude, $n=5$ ) (Fig. $5 H$ ). Together, these results suggest 


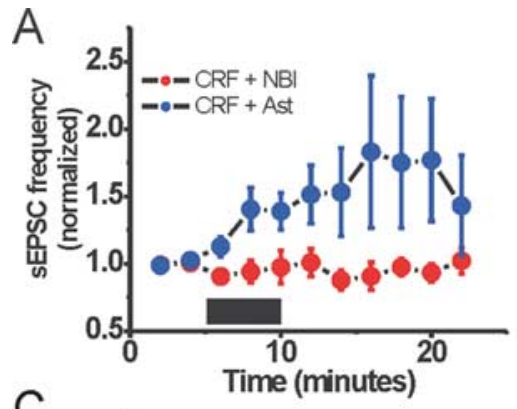

B
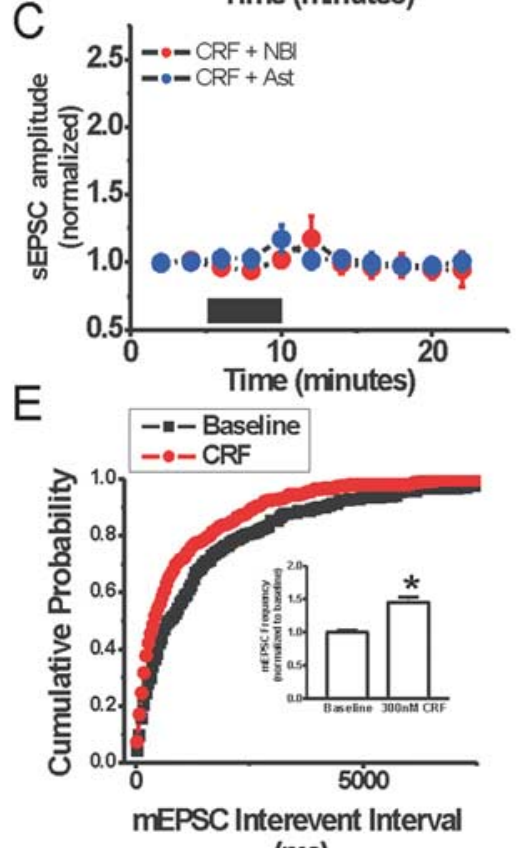

(ms)
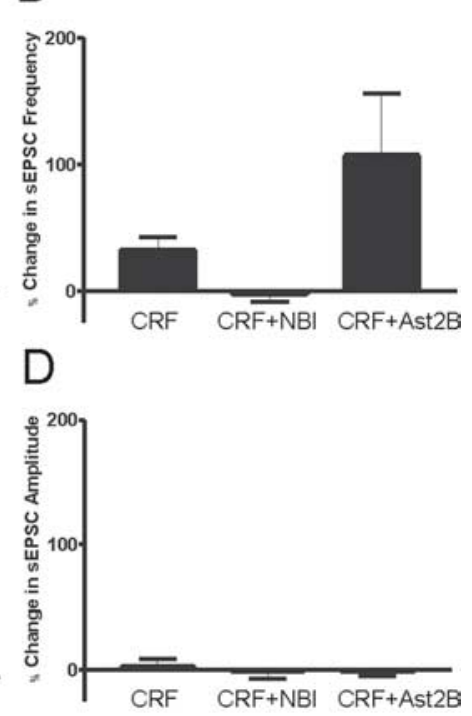

$\mathrm{F}$

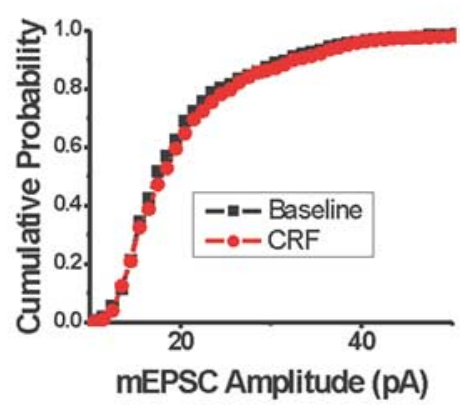

Figure 5. CRF acts via CRF-R1 receptors to enhance glutamate release in the dIBNST. $A$, CRF induced increase in sEPSC frequency is blocked by preapplication of the CRF-R1 selective antagonist, NBI27914, but persists in the presence of the CRF-R2 selective antagonist, Astressin-2B. B, Bar graph demonstrating the effects of CRF-R1 and CRF-R2 antagonism on the ability of $300 \mathrm{~nm}$ CRF to alter sEPSC frequency. C, CRF does not alter sEPSC amplitude in the presence of either NBI27914 or Astressin-2B. D, Bar graph demonstrating the effects of CRF-R1 and CRF-R2 antagonism on the ability of $300 \mathrm{~nm}$ CRF to alter sEPSC amplitude. $\boldsymbol{E}$, Bath application of $300 \mathrm{~nm}$ CRF results in a significant increase in mEPSC frequency as denoted by the shift in the cumulative probability distribution of the interevent interval. Inset, Bar graph demonstrating the average normalized increase in frequency $\left({ }^{*} p<0.05\right)$. $\boldsymbol{F}$, Bath application of $300 \mathrm{~nm}$ CRF does not result in a significant increase in mEPSC amplitude as denoted by the lack of a shift in the cumulative probability distribution of mEPSC amplitude.

that CRF is enhancing glutamate release through activation of CRF-R1 in the dlBNST.

\section{In vivo recruitment of catecholaminergic signaling in the BNST induces a NMDA-receptor dependent enhancement of short-term potentiation}

Both dopamine (Gao et al., 2006; Navakkode et al., 2007) and CRF (Blank et al., 2002; Ungless et al., 2003) have been previously suggested to modulate NMDA receptor (NMDAR)-dependent synaptic plasticity in other brain regions. In particular, in the hippocampus, CRF has been suggested to "prime" synapses for long-term potentiation (LTP) induction (Blank et al., 2002). To examine the effect of dopamine and CRF on synaptic plasticity in the dIBNST, we performed field recordings, as we have previously shown a robust form of stimulus induced LTP (Weitlauf et al., 2004). To begin to determine the consequences of in vivo elevation of extracellular dopamine levels in the BNST on glutamate synapses, we gave mice a single intraperitoneal (i.p.) injection of cocaine $(20 \mathrm{mg} / \mathrm{kg})$ or saline after $4 \mathrm{~d}$ of habituating saline injec- tions in a blinded design. After injection (30 $\mathrm{min}$ ) of cocaine or control saline, brain slices were prepared and electrophysiological recordings were performed as previously described to examine effects on stimulusevoked plasticity in the BNST (Weitlauf et al., 2004).

Local stimulation of the BNST elicits an extracellular field response consisting of two prominent downward deflections, much like in the striatum, which we refer to as $\mathrm{N} 1$ and N2 (Fig. 6A, inset). The N2, but not the N1, is eliminated by CNQX, suggesting that this portion is AMPAR mediated (Weitlauf et al., 2004; Grueter and Winder, 2005). Stimulation of glutamatergic afferents to the BNST with a moderate stimulus protocol (two $100 \mathrm{~Hz}$, $1 \mathrm{~s}$ trains with a $20 \mathrm{~s}$ interstimulus interval) elicits significant, stable, enhancement of the N2 without effect on the N1 (Fig. 6A, circles) $(n=12)$. This enhancement is NMDAR-dependent (Fig. 6D, closed squares) $(n=8)$ as previously described (Weitlauf et al., 2004). In animals receiving cocaine, there was transient $(\sim 20 \mathrm{~min})$ enhancement of the field potential posttetanus, which we refer to as STP (area under curve from minutes $0-20$ post-tetanus: saline, $517 \pm 104$ relative units, $n=$ 12 from 8 saline-treated animals; cocaine, $1097 \pm 193$ relative units, $n=7$ from 6 cocaine-treated animals, $p<0.01$ ) (Fig. 6A).

\section{Dopaminergic signaling within the dlBNST mediates cocaine enhancement of STP}

The in vivo effects of cocaine on subsequent ex vivo STP in BNST slices could reflect local actions of cocaine on catecholamine fibers in the BNST, or it could result from larger network effects of the in vivo cocaine. To differentiate between these possibilities, we prepared slices containing the BNST from naive mice, and bath applied cocaine before highfrequency stimulation. Addition of $3 \mu \mathrm{m}$ cocaine for $30 \mathrm{~min}$ did not alter basal transmission (Fig. $6 C$, squares) $(n=9)$; however, this cocaine application produced an enhancement of STP when a tetanus was given $60 \mathrm{~min}$ following washout (Fig. 6C) $(n=9)$ (Fig. $6 E, F)(n=14.37, p<0.01)$. This enhancement was specific to STP as LTP measured 50 min post-tetanus was not altered by cocaine (supplemental Fig. $1 C$, available at www.jneurosci.org as supplemental material) $(p=0.45)$. Blockade of NMDA receptors with DL-APV $(100 \mu \mathrm{M})$ similarly attenuated LTP whether cocaine was preapplied or not (Fig. $6 D)(n=8$ each) (Fig. $6 E$ ), suggesting that cocaine-induced enhancement of STP is NMDAR-dependent. Thus, the effect of ex vivo cocaine on STP was similar to the effects of in vivo cocaine administration.

In addition to dopaminergic input to the BNST there are also other monoaminergic inputs, including a dense projection of noradrenergic fibers from nucleus tractus solitarius (NTS) through the ventral noradrenergic bundle (Delfs et al., 2000) as 
well as a serotonergic input from the midbrain raphe nuclei (Commons et al., 2003). Because cocaine can act at multiple transporters, it is possible that the effect on STP could be mediated independently of dopamine. To further examine the role of dopamine in mediating enhanced plasticity in the dIBNST, we examined the ability of the DAT-selective antagonist, GBR12909, to alter STP. Consistent with our previous results, we found that bath application of GBR12909 before induction of LTP (Fig. 7A, time course of application) led to an enhancement of STP ( $p<$ 0.05, $n=8$ control, $n=6$ GBR12909) (Fig. $7 B)$. To further determine whether the dopamine system was responsible for cocaine-induced enhancement of STP, we applied the pan-dopamine receptor antagonist flupenthixol $(10 \mu \mathrm{M})$ with cocaine and observed that enhancement of STP was blocked (Fig. 7C) (flupenthixol and cocaine, $n=7$; cocaine, $n=16$ ) (Fig. $7 E, F)(n=6.43, p<0.05)$. We next examined the role of dopaminergic signaling in the mediation of the effects of in vivo cocaine administration by examining the ability of cocaine to alter STP in $\mathrm{D}_{1} \mathrm{R}$ KO mice. Consistent with our results obtained performing ex vivo cocaine application, we found that STP was not significantly enhanced in $\mathrm{D}_{1} \mathrm{R} \mathrm{KO}$ mice following injection of cocaine compared with saline injected mice (Fig. $7 F)(n=7$ from four cocaine-treated animals; $n=4$ from 3 saline-treated animals).

Based on our observation that CRF-R1 activation was necessary to produce dopaminergic enhancement of spontaneous glutamatergic transmission, we tested whether the cocaine enhancement of STP may also act via CRF-R1 signaling. Thus, we coapplied NBI27914 $(1 \mu \mathrm{M})$ in conjunction with cocaine and found that this manipulation also blocked cocaine-induced enhancement of STP (Fig. 7D) (NBI27914 and cocaine, $n=7$; cocaine, $n=16)($ Fig. $7 E, F)(n=6.43, p<0.05)$.

\section{Discussion}

Several lines of investigation indicate that a functional interaction between dopamine and CRF systems is involved in regulation of affective behavior, including drug abuse (Lu et al., 2003) and anxiety-like behavior (Meloni and Davis, 1999; Meloni et al., 2006). While several studies have elegantly demonstrated that $\mathrm{CRF}$ can regulate the activity of dopaminergic neurons (Ungless et al., 2003; Riegel and Williams, 2008; Wanat et al., 2008), to date, there is only one study examining the interaction of dopamine and CRF in the terminal field (Orozco-Cabal et al., 2008). We found that in the dlBNST, a component of the extended amygdala which is activated by drugs of abuse and innervated by dopaminergic fibers, low concentrations of dopamine enhance excitatory transmission through activation of endogenous CRF signaling. Additionally, we show that cocaine can enhance NMDAR-dependent potentiation transiently which we refer to as STP in the dlBNST through recruitment of endogenous dopamine and CRF signaling. These results identify an anatomically
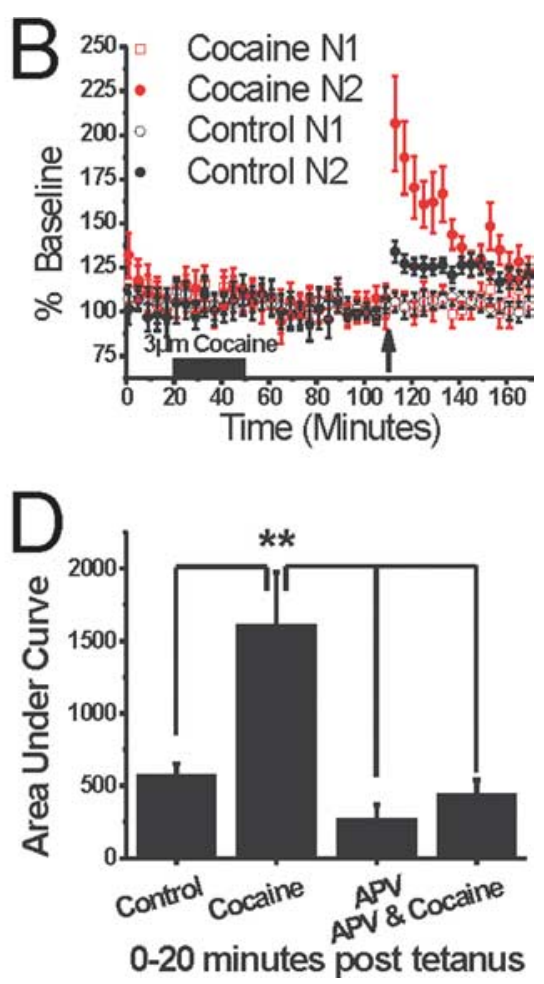

Figure 6. Cocaine produces an enhancement of NMDAR-dependent plasticity following tetanization in the dIBNST. A, Synaptic potentiation following tetanization (two $100 \mathrm{~Hz} 1 \mathrm{~s}$ trains with a 20 s interstimulus interval) in mice receiving an acute injection of (20 mg/kg) or saline 30 min before being killed. Inset, Representative traces $10 \mathrm{~min}$ after the tetanus depicting the Following tetanization enhanced potentiation was observed. Time-matched controls in which no drug was applied to the slice attenuates LTP both when cocaine was preapplied to slices and in slices naive to cocaine application. $D$, Quantification of effects in C and $\boldsymbol{D}\left(0-20\right.$ min post-tetanus, $\left.{ }^{* *} p<0.01\right)$.

distinct molecular mechanism by which the CRF system can alter the acute actions of drugs of abuse.

\section{Mechanism of enhancement of glutamatergic transmission}

Dopamine modulates synaptic transmission in different brain regions through a variety of mechanisms (Laviolette and Grace, 2006; Di Pietro and Seamans, 2007). We found that in the dIBNST, application of dopamine enhanced sEPSCs, but not mEPSCs through $\mathrm{D}_{1}$ - and $\mathrm{D}_{2}$-like receptor activation. Furthermore, the actions of dopamine appeared to be specific for excitatory transmission, as dopamine did not alter GABAergic transmission in the dIBNST (supplemental Fig. 2, available at www.jneurosci.org as supplemental material). Interestingly, the concentration of dopamine that elicited this effect in the dlBNST was similar to what has been shown to modulate synaptic transmission in the prefrontal cortex (Seamans et al., 2001). One potential reason underlying this similarity could be the reduced expression of the dopamine transporter relative to regions such as the striatum and nucleus accumbens (Healey et al., 2008). A cooperative requirement for $\mathrm{D}_{1}$ and $\mathrm{D}_{2}$ receptors in dopaminergic signaling has been previously shown in several brain regions, including the nucleus accumbens (Hopf et al., 2003) and prefrontal cortex (Wu and Hablitz, 2005). In particular, a study from Hopf et al. (2003) suggested that the cooperativity between $D_{1}$ and $\mathrm{D}_{2}$ receptors could be due to an intracellular signaling pathway interaction. Another potential reason for this interaction could be due to the presence $D_{1} / D_{2}$ heterodimeric receptors in the dlBNST, as have been seen in other brain regions (So et al., 

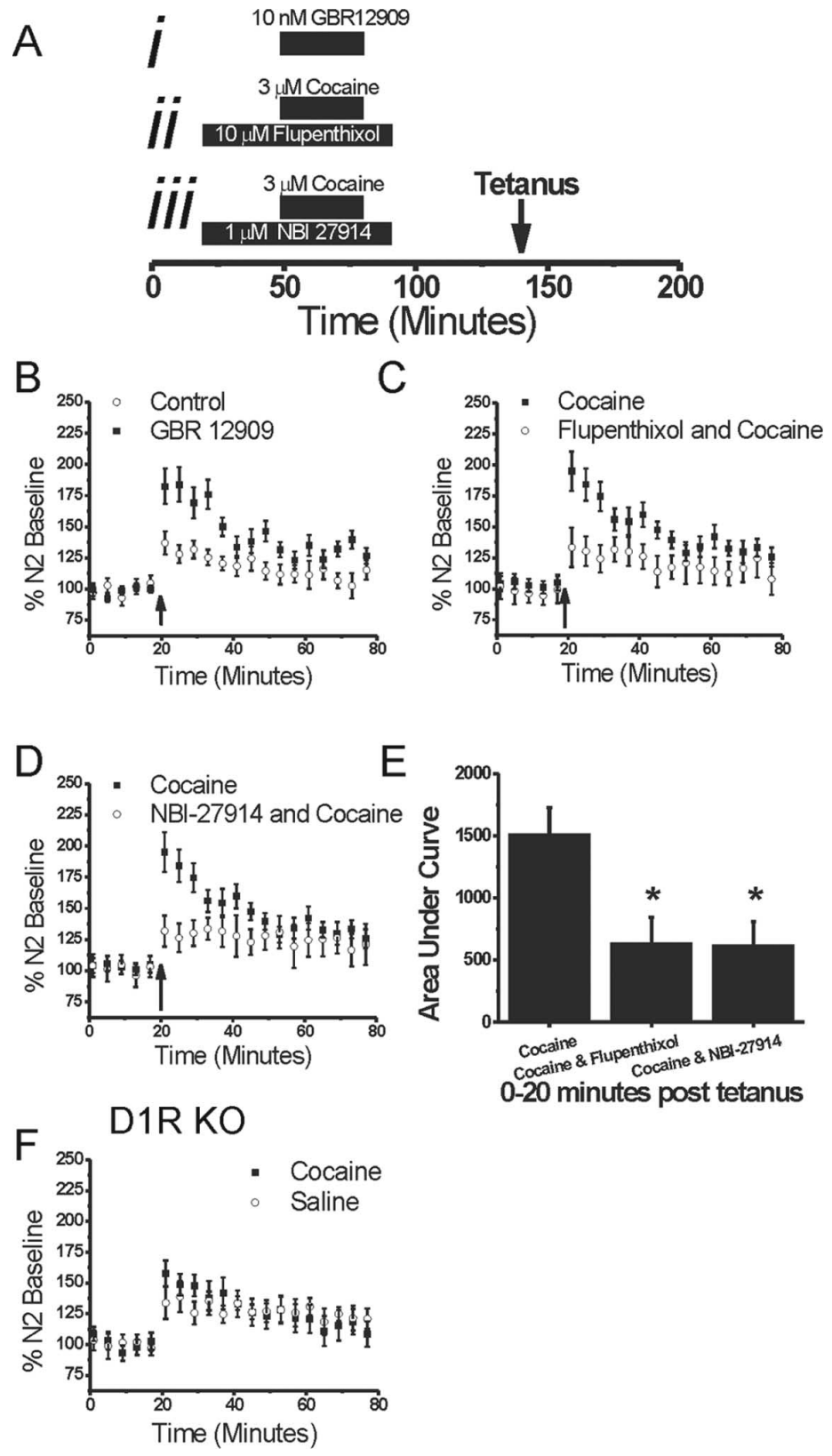

Figure 7. Cocaine-induced enhancement of plasticity is dependent on dopamine and CRFR1 signaling. A, Diagrammatic representation of the time course of experiments shown in this figure. The arrow indicates tetanization. $\boldsymbol{i}$, GBR12909 (10 nм) was bath applied for $30 \mathrm{~min}$ followed by a $60 \mathrm{~min}$ wash-out before tetanization. ii, Flupenthixol $(10 \mu \mathrm{m})$ was applied $30 \mathrm{~min}$ before cocaine followed by coapplication with cocaine. Antagonist was removed $10 \mathrm{~min}$ following the removal of cocaine, and tetanization was performed 50 min following removal of antagonist. iii, NBI27914 $(1 \mu \mathrm{m})$ was applied $30 \mathrm{~min}$ before cocaine followed by coapplication with cocaine. Antagonist was removed $10 \mathrm{~min}$ following the removal of cocaine, and tetanization was performed 50 min following removal of antagonist. $\boldsymbol{B}$, Following tetanization, enhanced short-term potentiation was observed following exposure to GBR12909. C, Following application of cocaine in the presence of the pan-dopamine receptor antagonist, flupenthixol, there was no alteration in plasticity following tetanus. $D$, Following application of cocaine in the presence of the CRFR1 antagonist, NBI27914, there was no alteration in plasticity following tetanus. $\boldsymbol{E}$, Quantification of effects of flupenthixol and NBI27914 on alterations in tetanus evoked plasticity following cocaine exposure $\left(0-20\right.$ min post-tetanus, $\left.{ }^{*} p<0.05\right)$. $F$, Synaptic potentiation following tetanization (two $100 \mathrm{~Hz} 1 \mathrm{~s}$ trains with a 20 s interstimulus interval) in $D_{1} \mathrm{R} K 0$ mice receiving an acute injection of cocaine $(20 \mathrm{mg} / \mathrm{kg})$ or saline $30 \mathrm{~min}$ before being killed.

2005). Although it is unclear whether similar mechanisms underlie the enhancement of glutamatergic transmission in the dIBNST, it is worth noting that both $\mathrm{D}_{1}$ and $\mathrm{D}_{2}$ receptors are enriched in the BNST (Wamsley et al., 1989; Hurd et al., 2001).

The lack of an effect of dopamine on mEPSCs raised the possibility that the enhancement we observed was activity- dependent, similar to the effects of dopamine on GABAergic transmission in the basolateral amygdala (Kröner et al., 2005). To probe this possibility, we next investigated the ability of dopamine to alter the excitable properties of neurons within the dlBNST using a current-clamp approach. We found that dopamine robustly depolarized only a subpopulation of neurons in the dIBNST. Given the diversity of celltypes in the dlBNST (Rainnie, 1999; Egli and Winder, 2003; Levita et al., 2004; Hammack et al., 2007), however, this was not necessarily a surprising result. Indeed, similar results were obtained when examining the ability of serotonin to modulate the excitable properties of neurons in the dIBNST (Levita et al., 2004). Several previous studies have suggested that dopamine fibers target CRF containing neurons in the dlBNST in the rat (Phelix et al., 1994; Meloni et al., 2006), a finding consistent with our results obtained in mouse. Based on this anatomical interaction, we hypothesized that dopamine could be enhancing excitatory transmission in the dlBNST via excitation of a distinct population of CRF positive neurons, causing them to release CRF, a known modulator of glutamatergic transmission (Ungless et al., 2003; Liu et al., 2004). In keeping with this, we found that a CRF-R1 antagonist blocked the ability of dopamine to enhance excitatory transmission, suggesting that dopamine was engaging endogenous CRF-R1 signaling systems to induce this effect. It should be noted that another model consistent with our data are that dopamine could depolarize CRF positive extrinsic afferents, such as those from the central nucleus of the amygdala (CeA), to enhance glutamatergic transmission, which has been proposed to be a critical molecular component of anxiety like behavior (Walker and Davis, 2008).

We went on to characterize the actions of CRF and found that it enhanced both sEPSC and mEPSC frequency, suggesting a presynaptic enhancement of function. Furthermore, we found that Urocortin I, an endogenous agonist of CRF receptors, enhanced spontaneous transmission in a similar manner. Similar actions of CRF have been reported in the CeA and the lateral septum mediolateral nucleus (Liu et al., 2004). Based on these findings, we speculate that the CRF-R1 that are mediating this increased glutamate release are localized on presynaptic glutamatergic terminals in the dIBNST. In support of this possibility, a recent study from the Vale group demonstrated with a mouse with green fluorescent protein (GFP) expression driven by a CRF-R1 promoter that within the dlBNST there is a dense network of GFP positive fibers (Justice et al., 2008). The authors went on to demonstrate that numerous GFP 
positive fibers were located close to CRF fibers, and support the possibility that CRF-R1 is localized in axon terminals. Indeed, a recent study hypothesized that CRF in the BNST can regulate glutamate release (Walker and Davis, 2008). These lines of evidence support the hypothesis that CRF-R1 are located on presynaptic terminals originates; however, future experiments will have to be performed to confirm this possibility. Similar to our findings in which both ex vivo and in vivo dopamine recruit CRF signaling, Nie et al. (2004) demonstrated that ex vivo application of ethanol led to a CRF-dependent enhancement of inhibitory synaptic transmission in the CeA in a CRF-R1 dependent manner. The differences seen between these studies reinforce the idea of critical region-specific effects of drugs of abuse and neuropeptides. Furthermore, it is unclear if this was due to engagement of endogenous dopaminergic signaling. Finally, based on our results it is difficult to determine if dopamine is enhancing CRF release or upregulating CRFR1 function; however, given the TTX-dependence of dopamine's action, an increase in CRF release is a more likely mechanism.

\section{Cocaine-induced enhancement of short-term potentiation}

Given the ability of dopamine receptor signaling in the BNST to modulate cocaine self-administration (Epping-Jordan et al., 1998), and previous studies that have demonstrated cocaine modulates plasticity (Thompson et al., 2005), we sought to determine the ability of cocaine to modulate plasticity in the dlBNST. We found that cocaine transiently enhanced the potentiation of synaptic transmission observed post-tetanus, which we have referred to as STP. Similar to the effect of cocaine on LTP in the hippocampus (Thompson et al., 2005), where dopamine acting at $\mathrm{D}_{2}$ receptors was required for enhancement of plasticity, we found that this cocaine enhancement of STP in the dlBNST also was dependent on activation of dopamine receptors. Additionally, we found that the cocaine enhancement of STP in the dlBNST was CRF-R1 dependent. Finally, the effect of in vivo cocaine exposure was mimicked by an ex vivo cocaine exposure, suggesting that endogenous dopamine in the dlBNST can regulate CRF activity. Based on these findings, our results suggests that, similar to the whole-cell experiments, cocaine enhances dopamine signaling which then recruits the activation of endogenous CRF signaling. Similar to our findings, it has been reported that in animals chronically exposed to cocaine there is an enhancement of LTP in the CeA that is dependent on CRF-R1 activation (Fu et al., 2007). Interestingly, while our results in the dIBNST indicate that dopamine-induced CRF signaling leads to an enhancement of STP, cocaine and CRF in both the hippocampus and the CeA lead to an enhancement of LTP.

While both dopamine and CRF have been shown to modulate induction of LTP, our results identify a novel mechanism, in which dopamine initiates a CRF-dependent enhancement of STP. This is particularly interesting as most studies investigating the interactions of dopamine and CRF have focused on the ability of CRF to influence DA neuron activity. This study provides the first electrophysiological evidence of a dopamine-induced CRFdependent phenomenon in naive animals. Together with a previous study that demonstrated dopamine receptor antagonism within the dlBNST alters cocaine self-administration (EppingJordan et al., 1998), these results suggest that DA-CRF signaling in the dlBNST is involved in mediating the rewarding aspects of acute cocaine. These results could also provide an anatomical site of action for the ability of CRF-R1 antagonism to impair the behavioral effects of cocaine and other abused drugs. This is particularly interesting, as a recent study has suggested that CRF-R1 activation is required for alcohol-induced neuroplasticity (Pastor et al., 2008).

\section{Network implications}

The dlBNST is exquisitely positioned to act as a relay between cortical regions associated with drug abuse, including the infralimbic and insular cortex (McDonald et al., 1999), and both the reward and stress systems (Walker and Davis, 2008). The brief enhancement of excitatory transmission brought about by CRF could engage a feedforward mechanism in which CRF from the BNST is activating DA neurons in the VTA, leading to increases in DA release in a number of critical target regions, including the prefrontal cortex, the nucleus accumbens and the BNST. A similar interaction between dopamine and CRF has been proposed to be involved in driving pathological anxiety-like behavior (Meloni et al., 2006). Together, these results suggest that identifying novel targets which impair this regulation could prove useful for treating both drug-addiction and anxiety disorders.

\section{References}

Blank T, Nijholt I, Eckart K, Spiess J (2002) Priming of long-term potentiation in mouse hippocampus by corticotropin-releasing factor and acute stress: implications for hippocampus-dependent learning. J Neurosci 22:3788-3794

Borgland SL, Taha SA, Sarti F, Fields HL, Bonci A (2006) Orexin A in the VTA is critical for the induction of synaptic plasticity and behavioral sensitization to cocaine. Neuron 49:589-601.

Carboni E, Silvagni A, Rolando MT, Di Chiara G (2000) Stimulation of in vivo dopamine transmission in the bed nucleus of stria terminalis by reinforcing drugs. J Neurosci 20:RC102.

Chen C, Dagnino R Jr, De Souza EB, Grigoriadis DE, Huang CQ, Kim KI, Liu Z, Moran T, Webb TR, Whitten JP, Xie YF, McCarthy JR (1996) Design and synthesis of a series of non-peptide high-affinity human corticotropinreleasing factor1 receptor antagonists. J Med Chem 39:4358-4360.

Choi DC, Furay AR, Evanson NK, Ostrander MM, Ulrich-Lai YM, Herman JP (2007) Bed nucleus of the stria terminalis subregions differentially regulate hypothalamic-pituitary-adrenal axis activity: implications for the integration of limbic inputs. J Neurosci 27:2025-2034.

Commons KG, Connolley KR, Valentino RJ (2003) A neurochemically distinct dorsal raphe-limbic circuit with a potential role in affective disorders. Neuropsychopharmacology 28:206-215.

Day HE, Curran EJ, Watson SJ Jr, Akil H (1999) Distinct neurochemical populations in the rat central nucleus of the amygdala and bed nucleus of the stria terminalis: evidence for their selective activation by interleukin1beta. J Comp Neurol 413:113-128.

Delfs JM, Zhu Y, Druhan JP, Aston-Jones G (2000) Noradrenaline in the ventral forebrain is critical for opiate withdrawal-induced aversion. Nature 403:430-434.

Di Pietro NC, Seamans JK (2007) Dopamine and serotonin interactions in the prefrontal cortex: insights on antipsychotic drugs and their mechanism of action. Pharmacopsychiatry 40 [Suppl 1]:S27-S33.

Dong HW, Swanson LW (2004) Organization of axonal projections from the anterolateral area of the bed nuclei of the stria terminalis. J Comp Neurol 468:277-298.

Egli RE, Winder DG (2003) Dorsal and ventral distribution of excitable and synaptic properties of neurons of the bed nucleus of the stria terminalis. J Neurophysiol 90:405-414.

Eiler WJ 2nd, Seyoum R, Foster KL, Mailey C, June HL (2003) D1 dopamine receptor regulates alcohol-motivated behaviors in the bed nucleus of the stria terminalis in alcohol-preferring (P) rats. Synapse 48:45-56.

Epping-Jordan MP, Markou A, Koob GF (1998) The dopamine D-1 receptor antagonist SCH 23390 injected into the dorsolateral bed nucleus of the stria terminalis decreased cocaine reinforcement in the rat. Brain Res 784:105-115.

Fu Y, Pollandt S, Liu J, Krishnan B, Genzer K, Orozco-Cabal L, Gallagher JP, Shinnick-Gallagher P (2007) Long-term potentiation (LTP) in the central amygdala (CeA) is enhanced after prolonged withdrawal from chronic cocaine and requires CRF1 receptors. J Neurophysiol 97:937-941.

Gao C, Sun X, Wolf ME (2006) Activation of D1 dopamine receptors increases surface expression of AMPA receptors and facilitates their synaptic incorporation in cultured hippocampal neurons. J Neurochem 98:1664-1677.

Georges F, Aston-Jones G (2002) Activation of ventral tegmental area cells 
by the bed nucleus of the stria terminalis: a novel excitatory amino acid input to midbrain dopamine neurons. J Neurosci 22:5173-5187.

Grueter BA, Winder DG (2005) Group II and III metabotropic glutamate receptors suppress excitatory synaptic transmission in the dorsolateral bed nucleus of the stria terminalis. Neuropsychopharmacology 30:1302-1311.

Hammack SE, Mania I, Rainnie DG (2007) Differential expression of intrinsic membrane currents in defined cell types of the anterolateral bed nucleus of the stria terminalis. J Neurophysiol 98:638-656.

Healey JC, Winder DG, Kash TL (2008) Chronic ethanol exposure leads to divergent control of dopaminergic synapses in distinct target regions. Alcohol 42:179-190.

Hopf FW, Cascini MG, Gordon AS, Diamond I, Bonci A (2003) Cooperative activation of dopamine $\mathrm{D}_{1}$ and $\mathrm{D}_{2}$ receptors increases spike firing of nucleus accumbens neurons via G-protein $\beta \gamma$ subunits. J Neurosci 23:5079-5087.

Hurd YL, Suzuki M, Sedvall GC (2001) D1 and D2 dopamine receptor mRNA expression in whole hemisphere sections of the human brain. J Chem Neuroanat 22:127-137.

Justice NJ, Yuan ZF, Sawchenko PE, Vale W (2008) Type 1 corticotropinreleasing factor receptor expression reported in BAC transgenic mice: implications for reconciling ligand-receptor mismatch in the central corticotropin-releasing factor system. J Comp Neurol 511:479-496.

Kash TL, Winder DG (2006) Neuropeptide Y and corticotropin-releasing factor bi-directionally modulate inhibitory synaptic transmission in the bed nucleus of the stria terminalis. Neuropharmacology 51:1013-1022.

Kash TL, Matthews RT, Winder DG (2008) Alcohol inhibits NR2Bcontaining NMDA receptors in the ventral bed nucleus of the stria terminalis. Neuropsychopharmacology 33:1379-1390.

Kauer JA, Malenka RC (2007) Synaptic plasticity and addiction. Nat Rev Neurosci 8:844-858.

Kröner S, Rosenkranz JA, Grace AA, Barrionuevo G (2005) Dopamine modulates excitability of basolateral amygdala neurons in vitro. J Neurophysiol 93:1598-1610.

Laviolette SR, Grace AA (2006) The roles of cannabinoid and dopamine receptor systems in neural emotional learning circuits: implications for schizophrenia and addiction. Cell Mol Life Sci 63:1597-1613.

Levita L, Hammack SE, Mania I, Li XY, Davis M, Rainnie DG (2004) 5-Hydroxytryptamine1A-like receptor activation in the bed nucleus of the stria terminalis: electrophysiological and behavioral studies. Neuroscience 128:583-596.

Liu J, Yu B, Neugebauer V, Grigoriadis DE, Rivier J, Vale WW, ShinnickGallagher P, Gallagher JP (2004) Corticotropin-releasing factor and Urocortin I modulate excitatory glutamatergic synaptic transmission. J Neurosci 24:4020-4029.

Lu L, Liu Z, Huang M, Zhang Z (2003) Dopamine-dependent responses to cocaine depend on corticotropin-releasing factor receptor subtypes. J Neurochem 84:1378-1386.

Malenka RC, Nicoll RA (1986) Dopamine decreases the calcium-activated afterhyperpolarization in hippocampal CA1 pyramidal cells. Brain Res 379:210-215.

McDonald AJ, Shammah-Lagnado SJ, Shi C, Davis M (1999) Cortical afferents to the extended amygdala. Ann N Y Acad Sci 877:309-338.

Meloni EG, Davis M (1999) Enhancement of the acoustic startle response in rats by the dopamine D1 receptor agonist SKF 82958. Psychopharmacology (Berl) 144:373-380.

Meloni EG, Gerety LP, Knoll AT, Cohen BM, Carlezon WA Jr (2006) Behavioral and anatomical interactions between dopamine and corticotropin-releasing factor in the rat. J Neurosci 26:3855-3863.

Navakkode S, Sajikumar S, Frey JU (2007) Synergistic requirements for the induction of dopaminergic D1/D5-receptor-mediated LTP in hippocampal slices of rat CA1 in vitro. Neuropharmacology 52:1547-1554.

Nie Z, Schweitzer P, Roberts AJ, Madamba SG, Moore SD, Siggins GR (2004) Ethanol augments GABAergic transmission in the central amygdala via CRF1 receptors. Science 303:1512-1514.

Orozco-Cabal L, Liu J, Pollandt S, Schmidt K, Shinnick-Gallagher P, Gallagher JP (2008) Dopamine and corticotropin-releasing factor synergistically alter basolateral amygdala-to-medial prefrontal cortex synaptic transmission: functional switch after chronic cocaine administration. J Neurosci 28:529-542.

Pastor R, McKinnon CS, Scibelli AC, Burkhart-Kasch S, Reed C, Ryabinin AE, Coste SC, Stenzel-Poore MP, Phillips TJ (2008) Corticotropin-releasing factor-1 receptor involvement in behavioral neuroadaptation to ethanol: a urocortin1-independent mechanism. Proc Natl Acad Sci U S A 105:9070-9075.

Phelix CF, Liposits Z, Paull WK (1994) Catecholamine-CRF synaptic interaction in a septal bed nucleus: afferents of neurons in the bed nucleus of the stria terminalis. Brain Res Bull 33:109-119.

Rainnie DG (1999) Neurons of the bed nucleus of the stria terminalis (BNST). Electrophysiological properties and their response to serotonin. Ann N Y Acad Sci 877:695-699.

Riegel AC, Williams JT (2008) CRF facilitates calcium release from intracellular stores in midbrain dopamine neurons. Neuron 57:559-570.

Rodaros D, Caruana DA, Amir S, Stewart J (2007) Corticotropin-releasing factor projections from limbic forebrain and paraventricular nucleus of the hypothalamus to the region of the ventral tegmental area. Neuroscience 150:8-13.

Sarnyai Z, Shaham Y, Heinrichs SC (2001) The role of corticotropinreleasing factor in drug addiction. Pharmacol Rev 53:209-243.

Seamans JK, Gorelova N, Durstewitz D, Yang CR (2001) Bidirectional dopamine modulation of GABAergic inhibition in prefrontal cortical pyramidal neurons. J Neurosci 21:3628-3638.

So CH, Varghese G, Curley KJ, Kong MM, Alijaniaram M, Ji X, Nguyen T, O'dowd BF, George SR (2005) D1 and D2 dopamine receptors form heterooligomers and cointernalize after selective activation of either receptor. Mol Pharmacol 68:568-578.

Specio SE, Wee S, O’Dell LE, Boutrel B, Zorrilla EP, Koob GF (2008) CRF(1) receptor antagonists attenuate escalated cocaine self-administration in rats. Psychopharmacology (Berl) 196:473-482.

Stanwood GD, Parlaman JP, Levitt P (2006) Genetic or pharmacological inactivation of the dopamine D1 receptor differentially alters the expression of regulator of G-protein signalling (Rgs) transcripts. Eur J Neurosci 24:806-818.

Thomas MJ, Beurrier C, Bonci A, Malenka RC (2001) Long-term depression in the nucleus accumbens: a neural correlate of behavioral sensitization to cocaine. Nat Neurosci 4:1217-1223.

Thompson AM, Swant J, Wagner JJ (2005) Cocaine-induced modulation of long-term potentiation in the CA1 region of rat hippocampus. Neuropharmacology 49:185-194.

Ungless MA, Whistler JL, Malenka RC, Bonci A (2001) Single cocaine exposure in vivo induces long-term potentiation in dopamine neurons. Nature 411:583-587.

Ungless MA, Singh V, Crowder TL, Yaka R, Ron D, Bonci A (2003) Corticotropin-releasing factor requires $\mathrm{CRF}$ binding protein to potentiate NMDA receptors via CRF receptor 2 in dopamine neurons. Neuron 39:401-407.

Valjent E, Pagès C, Hervé D, Girault JA, Caboche J (2004) Addictive and non-addictive drugs induce distinct and specific patterns of ERK activation in mouse brain. Eur J Neurosci 19:1826-1836.

Vaughan J, Donaldson C, Bittencourt J, Perrin MH, Lewis K, Sutton S, Chan R, Turnbull AV, Lovejoy D, Rivier C, Rivier J, Sawchenko PE, Vale W (1995) Urocortin, a mammalian neuropeptide related to fish urotensin I and to corticotropin-releasing factor. Nature 378:287-292.

Walker DL, Davis M (2008) Role of the extended amygdala in shortduration versus sustained fear: a tribute to Dr. Lennart Heimer. Brain Struct Funct 213:29-42.

Walker DL, Toufexis DJ, Davis M (2003) Role of the bed nucleus of the stria terminalis versus the amygdala in fear, stress, and anxiety. Eur J Pharmacol 463:199-216.

Wamsley JK, Gehlert DR, Filloux FM, Dawson TM (1989) Comparison of the distribution of D-1 and D-2 dopamine receptors in the rat brain. J Chem Neuroanat 2:119-137.

Wanat MJ, Hopf FW, Stuber GD, Phillips PE, Bonci A (2008) Corticotropin-releasing factor increases mouse ventral tegmental area dopamine neuron firing through a protein kinase $\mathrm{C}$-dependent enhancement of Ih. J Physiol 586:2157-2170.

Weitlauf C, Egli RE, Grueter BA, Winder DG (2004) High-frequency stimulation induces ethanol-sensitive long-term potentiation at glutamatergic synapses in the dorsolateral bed nucleus of the stria terminalis. J Neurosci 24:5741-5747.

Wu J, Hablitz JJ (2005) Cooperative activation of $\mathrm{D}_{1}$ and $\mathrm{D}_{2}$ dopamine receptors enhances a hyperpolarization-activated inward current in layer I interneurons. J Neurosci 25:6322-6328. 